\title{
Complexity of the Diagnosis of COVID-19 in the Context of Pandemicity: Need for Excellence in Diagnostic Acumen
}

\author{
Suresh K. Joishy', Michito Sadohara ${ }^{2}$, Masaru Kurihara ${ }^{3}$, Yasuharu Tokuda ${ }^{4, *}$ \\ ${ }^{1}$ Former Medical Staff, Veterans Health Administration Hospital, Salt Lake City, UT, USA \\ ${ }^{2}$ Department of Medical Education, Kumamoto University Hospital, Kumamoto, Japan \\ ${ }^{3}$ Department of Hospital Medicine, Urasoe General Hospital, Urasoe, Japan \\ ${ }^{4}$ Department of Medicine, Muribushi Okinawa Center for Teaching Hospitals, Urasoe, Japan
}

Coronavirus disease 2019 (COVID-19) is a highly infectious disease that has caused a pandemic devastating many countries worldwide. It is a complex and multifaceted disease with a unique coronavirus etiology, pathogenesis, zoonotic, and human-to-human transmission, causing acute respiratory distress syndrome with high mortality. Accurate and timely diagnosis is of utmost importance. In this study, we discussed the complexities of COVID-19 diagnostic elements in the context of pandemicity, drawing from our awareness, observations, and lessons learned from two previous coronavirus pandemics, namely SARS-CoV (severe acute respiratory syndrome coronavirus) in 2002 and MERS-CoV (Middle East respiratory syndrome-related coronavirus) in 2012, and how they applied to the diagnosis of COVID-19 today. Diagnosis of COVID-19 takes place without physician-patient personal contact due to isolation or quarantine or in the hospital setting, emergency units, and critical care units with the cumbersome barriers of personal protective equipment. Technical diagnosis is important, but we also emphasized the human impact of diagnosing COVID-19. Conveying the diagnosis of a critical disease to patients and families requires aspects of excellence in professionalism: ethics, empathy, and humility. Diagnostic skills in COVID-19 should extend to prognostication for patients suffering at the end of life, so that they will not be deprived of high-quality palliative care and comfort.

Keywords: Diagnosis; Severe Acute Respiratory Syndrome; Middle East Respiratory Syndrome Coronavirus; SARSCoV-2; COVID-19; Terminal Care 


\section{INTRODUCTION}

Diagnosis of coronavirus disease 2019 (COVID-19) is complex and challenging due to a wide spectrum of disease manifestations, severe and unpredictable prognosis, rapid spread worldwide within a matter of weeks to months, and the overwhelming magnitude of mortality. These features were first published and updated by the Chinese Center for Disease Control in a record-breaking case series of 72,314 patients in mainland China, where the epidemic started in Wuhan province. $^{1)}$

Wu and McGoogan ${ }^{2)}$ published the same series of 72,314 cases of COVID-19 from data established by the Chinese Center for Disease Control. This is the most comprehensive study on COVID-19 available today, covering epidemiology, etiology, viral identification, gene sequencing, development of molecular testing by reverse transcriptasepolymerase chain reaction (RT-PCR), laboratory diagnosis, radiological imaging studies, pathogenesis of acute respiratory distress syndrome, hospital management, and outcomes. Equally importantly, they set guidelines for the control of the epidemic by testing, tracking, tracing, and syndromic containment by isolation and quarantine. At the time of writing, China, Singapore, and South Korea seem to have contained this pandemic. ${ }^{3)}$

We cite more scholarly reviews and guidelines in the discussion section. However, English literature reviews and discourses are overwhelmingly repetitive based on Chinese foundational work. Why then, this study on COVID-19? COVID-19 is a complex infectious disease that has caused a pandemic. Clinically, it can be benign, very mild to the most severe, and lethal. It is a systemic disease where processes, mechanisms, and molecules at multiple levels act simultaneously at non-acceptable, non-normal levels, as stated by Vihinen from Sweden. $^{4)}$

There is a wide gap in the literature regarding the complexities of COVID-19 and diagnostic elements required for accurate and timely diagnosis without dilemmas and delays. We clarify the diagnostic elements of COVID-19 from our collective recall of clinical observations of previous coronavirus pandemics of this century, namely severe acute respiratory syndrome (SARS) ${ }^{5)}$ and Middle East respiratory syndrome (MERS). ${ }^{6)}$ In addition, the purpose of this study was to clarify how the diagnostic elements of mainstream diseases are affected by the complexities of COVID-19. We examined the pandemic aspects of COVID-19 through a diagnostic lens, and then generated a diagnostic triad-the virus, patients, and lungs—-that determine the prognosis. We describe the impact of the diagnosis, tangibles and intangibles, and the need for ethics and empathy. Finally, we propose to include diagnostic elements to recognize the physical, psychosocial, and spiritual issues and end-of-life palliative care until we have a cure or prophylaxis.

\section{DIAGNOSIS OF COVID-19}

The database in the literature on diagnosis and diagnostics is huge, with reviews and guidelines. Wu and McGoogan. ${ }^{2)}$ presented a review of 72,314 patients from China. Borges do Nascimento et al. ${ }^{7)}$ conducted a scoping review and meta-analysis of 61 studies involving 59,254 patients. They presented a triple algorithm for diagnosis involving epidemiological history, clinical symptoms, and laboratory/radiological findings. From New York City in the United States, Richardson et al. ${ }^{8)}$ presented a study of 5,700 patients, analyzing the clinical picture, treatments of critical disease, and outcomes. Their experience of the clinical picture of COVID-19, mild/moderate/severe disease, and diagnostic features were quite similar to Chinese experience in the initial phase of the COVID-19 pandemic.

We also reviewed experiences from other countries that were affected by COVID-19. Song et al. ${ }^{9)}$ reported their experiences in South Korea after the first case on January 20, 2020. Their main concern was delay in diagnosis, and they classified patients as susceptible, self-quarantine-susceptible, exposed, infectious with timely diagnosis, infectious with delayed diagnosis, hospitalized, recovered, or died. ${ }^{9)}$ Lum and Tambyah ${ }^{10)}$ from Singapore reported confidence in controlling COVID-19 from the previous experience of coronavirus SARS pandemic in 2003. They were prepared to diagnose COVID-19 with molecular testing RT-PCR, even before the first case was detected. ${ }^{10)}$ In a report of Furuse et al. ${ }^{11)}$ from Japan on the outbreak of COVID-19 from January to March 2020, after the first case was diagnosed on January 15, 2020, 2,175 cases tested positive, with 56 deaths. In Europe, Italy and Spain were the worst hit by COVID-19, as reported by Saglietto et al. ${ }^{12)}$ from Italy. It is still useful to read the "World Health Organization (WHO) report of the joint mission with China on coronavirus disease 2019" to obtain a broad perspective on the science of developing diagnostic studies. ${ }^{13)}$ British Medical Journal (BMJ) puts it all together on COVID-19 in a best practice series that can be read by any specialty, including pediatrics. ${ }^{14)}$ The Centers for Disease Control and Prevention (CDC) in Atlanta, Georgia, United States maintains a busy website on almost any topic on COVID-19, including evaluation and testing. ${ }^{15)}$

After a thorough review of the aforementioned literature, we studied the guidelines from national and international agencies. The Infectious Disease Society of America recommends nucleic acid testing of all symptomatic patients, individuals suspected of having contact with COVID-19 patients, or people who traveled to infected areas. They offer 15 recommendations for nucleic acid testing using an algorithmic diagram. They also have excellent guidelines for isolation, quarantine, personal protective equipment (PPE) usage, eligibility for surgery, immunosuppressive therapy, and so forth. ${ }^{16)}$ Other useful guidelines include the $\mathrm{CDC},{ }^{17)}$ WHO Technical Guidelines, ${ }^{18)}$ and National Institute for Health Care and Excellence in the United Kingdom. ${ }^{19)}$ Chavez et al. ${ }^{20)}$ laid down useful guidelines for the diagnosis and prediction of disease progression in the emergency room where a considerable number of COVID-19 patients were seen.

Jiang et al. ${ }^{21)}$ recently reviewed the clinical characteristics of coronavirus diagnosis and summarized them in a few steps. The first step was to recognize the respiratory symptoms. The second was to identify contact or history of travel to any area where COVID-19 was detected, 
and then conduct timely molecular tests and inform public health authorities. Patient care can be assessed by wearing PPE or distant diagnosis. ${ }^{21)}$ Having reviewed the aforementioned scholarly discourses and guidelines on COVID-19, in this study, we address the diagnosis of COVID-19 from an experienced physician's point of view. Our work may facilitate the education of physicians, residents, and medical students on the front line, who might not have experienced the other two coronavirus pandemics of this century.

The medical profession has not been well trained for diagnosing infectious diseases in a context of a pandemic. Clarification is needed to diagnose infection in the context of a pandemic. Card ${ }^{22)}$ states that pandemicity and infection are separate constructs. The geographic scale is the defining characteristic of pandemicity and not severity. A pandemic is a large epidemic. ${ }^{22)}$ The magnitude of severity of COVID-19 for diagnosis is as follows: Anthony Fauci, the chief of the Panel on COVID-19 in the United States, with his colleagues ${ }^{23)}$ reported in the New England Journal of Medicine, on March 28, 2020 that the total number of COVID-19 patients diagnosed in the United States on February 26, 2020 was 62 . The CDC in the United States on May 31, 2020 (about 3 months after the report of Fauci et al. ${ }^{23)}$ ) revealed that there were 1,761,503 cases, and 103,700 patients died. ${ }^{24)}$ Lippi et al. ${ }^{25)}$ called this a "perfect storm." Therefore, diagnosing the disease with a molecular test and naming it COVID-19 is insufficient. We need to diagnose a "full blown disease" in this perfect storm. The diagnosis requires full knowledge of the disease, its high risk of human-to-human transmission, existence of asymptomatic carriers, viral shedding days after symptom relief requiring isolation, quarantine, environmental transmission, viral biology, pathogenesis host immunopathology, rapid progression to acute respiratory distress syndrome (ARDS), and high mortality even after intensive care. ${ }^{25)}$ Wynants et al. ${ }^{26)}$ presented an indepth systematic literature review of COVID-19 diagnosis and classified diagnostic models, including machine learning-based mortality risks and progression to severity. However, they concluded that all were poorly reported and a high risk of bias was present. ${ }^{26)}$

COVID-19 has emerged as an acute, highly infectious, and lifethreatening disease in a context of a pandemic. We diagnosed and managed similar critical infections with pneumonia and septic shock regularly in tertiary care hospital emergency rooms and intensive care units (ICUs). The diagnosis of COVID-19 is different in that impeccable diagnostic acumen is needed. The authors of this study clarify the diagnostic acumen based on their own experiences in clinical diagnoses of acute and life-threatening illness in internal medicine, hematology and oncology, emergency medicine, and public health from diverse geographic regions in the world.

\section{DIAGNOSTIC ACUMEN REQUIRED FOR COVID-19}

The Collins English Dictionary describes acumen as the ability to make good judgment and quick decisions. ${ }^{27)}$ Merriam Webster Dictionary defines acumen as keenness and depth of perception, discernment, or discrimination especially on practice matters. ${ }^{28)}$ Considering the emergent nature of COVID-19, diagnostic acumen refers to how accurately and how quickly a physician recognizes and treats COVID-19.

\section{PARADIGM SHIFTS IN DIAGNOSTIC ACUMEN FOR COVID-19}

All physicians possess diagnostic acumen to assess, diagnose, and treat what we will refer to as "mainstream diseases." The nature of COVID-19 requires some changes in its diagnostic elements. For example, the traditional diagnosis of a disease requires symptom recognition by person-to-person history taking, physical examination, laboratory and radiological studies, and confirmation of the disease for treatment. COVID-19, however, may exist in the presymptomatic phase or be asymptomatic. Due to isolation and quarantine, face-to-face interactions and physical examination may not be possible. Remote consultation and video observation of the patient may be preferred if resources exist. Diagnostic experience is fragmented due to the unpredictable nature of COVID-19, along with development of "front line" providers and paramedical professionals and even medical students. Usually, diagnosis can predict prognosis for most patients with mainstream diseases but not for those with COVID-19. Diagnosis generally matches treatment for mainstream diseases. Molecular diagnostic tests and radiographic studies are not $100 \%$ accurate for COVID-19. ${ }^{29}$

The molecular test may be specific to COVID-19, but it is not a good standard because it recognizes only viral RNA and not infectivity. A detailed discourse on laboratory tests is beyond the scope of this study, but Watson et al. ${ }^{30)}$ provide good decision making based on test results. Patel et al. ${ }^{31)}$ gave us a very useful report from the American Society for Microbiology on the COVID-19 international summit on March 23, 2020. They responded to some challenging questions: when to test, whom to test, how often to test, and what should be done with the test results ${ }^{31)}$ We have compared the diagnostic acumen traditionally applied to diagnose mainstream diseases with the acumen required to diagnose the complexities of COVID-19 in the context of a pandemic in Table 1.

Time to time, clues appear in medical literature, also popularized by news media and social media, such as olfactory dysfunction, anosmia, or dysgeusia. Whitcroft and Hummel ${ }^{32)}$ best described olfactory dysfunction using diagnostic methods and even recommendations for management. Galvan Casas et al. ${ }^{33)}$ described patterns of dermatological lesions in 375 patients.

\section{DIAGNOSTIC ACUMEN AND NAMING THE DISEASE ACCURATELY IN CLINICAL RECORDS AND DEATH CERTIFICATES}

Clinical literature, news media, and social media are saturated with information on COVID-19. Naming the disease varies in citations in this article as well: severe acute respiratory syndrome coronavirus 2 (SARSCoV-2), novel coronavirus disease (NCov), coronavirus disease 2019, 
Table 1. Complexities of COVID-19 diagnostic elements compared with mainstream diseases

\begin{tabular}{|c|c|c|}
\hline Diagnostic elements & Mainstream diseases & COVID-19/pandemic \\
\hline Symptoms & Disease specific indicative clues & Non-specific/respiratory \\
\hline Thorough clinical history & Clinical diagnostic clues & Few diagnostic clues \\
\hline Clinical interview & Face to face & Limitations: mask/gloves/PPE/quarantine \\
\hline Etiology/pathogenesis & $\begin{array}{l}\text { Infection/inflammation; cancer; degenerative; endocrine/metabolic; } \\
\text { organ specific/systemic; idiopathic }\end{array}$ & $\begin{array}{l}\text { SARS-CoV-2; epidemic/pandemic context; lung specific; systemic } \\
\text { in severe disease }\end{array}$ \\
\hline Diagnostic experience & Decades/centuries & New since SARS-CoV-2003 \\
\hline Prognosis & $\begin{array}{l}\text { Predictable; march of events; trajectories; prognostic indices; } \\
\text { acute/chronic }\end{array}$ & Unpredictable; mild/moderate/severe/critical \\
\hline Investigations & "Gold standard tests" & Tests still evolving $<100 \%$ accuracy \\
\hline Diagnostic communication & Patient centered; family oriented & Barriers to patient-centeredness; remote/telemedicine \\
\hline Diagnostic outcome/treatments & $\begin{array}{l}\text { Cure/prophylaxis; complete/partial response; refractory; end-of- } \\
\text { life; palliative care; evidence-based medicine }\end{array}$ & $\begin{array}{l}\text { No cure/prophylaxis yet; high level of refractory disease and short } \\
\text { survival in critical care; missed out palliative at the end-of-life; } \\
\text { yet to develop evidence-based medicine }\end{array}$ \\
\hline
\end{tabular}

COVID-19, coronavirus disease 2019; PPE, personal protective equipment; SARS-CoV-2, severe acute respiratory syndrome coronavirus 2.

or just COVID-19. As the current coronavirus disease occurred in 2019, it was named COVID-19 by the WHO. The WHO also stated that the International Committee on Taxonomy of Viruses named the virus SARS-CoV-2 because this is the second pandemic caused by a severe acute respiratory syndrome coronavirus (SARS-CoV) since 2003, though it is a mutated version with $85 \%$ homology. There was another acute respiratory syndrome in the Middle East; perhaps because it was not so severe, they dropped the word 'severe' and called the virus that caused the disease Middle East respiratory syndrome coronavirus, or MERS-CoV. ${ }^{34}$

From our understanding, the virus is called 'novel' only when it is newly discovered and not novel anymore after we have sufficient information about it. We feel that we have enough information about COVID-19, there is nothing 'novel' about it. Helmy et al. provided a comprehensive review of taxonomy, genetics, epidemiology, diagnosis, treatment, and control of COVID-19. ${ }^{35)}$ For the purpose of diagnostic acumen, we will call the disease simply COVID-19, with no preceding or following words.

\section{DIAGNOSTIC ACUMEN RECALLS PAST EXPERIENCE TO APPLY IN DIAGNOSIS OF NEW DISEASES}

Diagnostic acumen involves the ability of clinicians to recall past experiences and reflect on comparative features of this infectious disease in the context of a pandemic. What Greenberg et al. ${ }^{36)}$ said in 2003 in the New England Journal of Medicine about SARS applies today for COVID-19: "Faster. Fast enough?" We are not diagnosing COVID-19 quickly enough. SARS was contained by strict tracking, tracing, and quarantine methods in China and Singapore, as well as a few hundred patients in the Unites States. No vaccine or drugs have been developed, and SARS has not recurred since 2003. Wilder-Smith et al. ${ }^{37)}$ also wonders, writing in Lancet recently, "Can we contain COVID-19 outbreak with the same means as the SARS?" A report of Wong and $\mathrm{Hui}^{38)}$ in 2003 on the epidemiology, diagnosis, and management of SARS will appear as if it were written today if the term SARS is substituted by COVID-19. Contini et al. ${ }^{39)}$ wrote an excellent review of all three coronavirus pandemics, namely SARS, MERS, and COVID-19. All three are similar in etiology. When severe, the common denominator is ARDS, and mortality is high in patients with severe disease. SARS was diagnosed in 328 patients in the United States ${ }^{40)}$ and MERS in two patients. ${ }^{41)}$

\section{DEALING WITH DILEMMAS, DELAYS, AND DISCORDANCE IN THE DIAGNOSIS OF COVID-19}

The main dilemma is the diagnosis of viral shedding or infectivity. Molecular testing is accurate to the extent of viral RNA, but not infectivity. It is of great importance for contact tracing, isolation of exposed individual social distancing, and essential public health measures to prevent further spread. Widders et al. ${ }^{42)}$ address the challenges in diagnosis.

\section{DIAGNOSTIC ACUMEN MEANS COMPLETE CLINICAL ASSESSMENT OF PATIENTS ACCURATELY AND WITHOUT DELAY}

In addition to timely diagnosis and prevention of delays, the accuracy of COVID diagnosis is critical. Gandhi and Singh ${ }^{43)}$ proposed eight categories of errors anticipated in COVID-19 diagnosis and proposed a user-friendly nomenclature: classic presentation with respiratory symptoms, anomalous/missed or delayed with non-respiratory symptoms, anchor/diagnosis on assumption, second/missed secondary diagnosis in a patient being treated for COVID-19, acute collateral/patients are not coming for evaluation due to fear of contracting infection, chronic collateral/cancelled appointments, strain/health care system overwhelmed, and unintended/less direct interaction due to telemedicine. In a pandemic like the COVID-19 pandemic, the entire population is at risk of transmission and infection. Rong et al. ${ }^{44)}$ categorized patients as susceptible, exposed, infectious with timely or de- 
layed diagnosis, hospitalized, recovered, symptomatic, or asymptomatic. They aptly put it, the diagnosis should be systematic, scientific, and normative and should work perfectly. ${ }^{44)}$ Diagnosing COVID-19 with or without evidence-based medicine requires diagnostic acumen. Because there are so many variables and complexities, we pass them through a diagnostic analytical lens, subject them to diagnostic acumen, and arrive at the diagnosis of COVID-19 with a focus on the patient (Figure 1).

\section{DIAGNOSTIC ACUMEN TO UNDERSTAND HUMAN IMPACT OF THE DIAGNOSIS OF COVID-19 ON THE PATIENT}

Epidemiology, statistics, molecular testing, radiology, or emerging new diagnostic tests have no meaning unless we have the diagnostic acumen to recognize and act upon the human impact of COVID-19 diagnosis on patients. The most important impact is the prognosis. Prognosis as a part of the diagnosis is inseparable. When diagnosis is obtained, the first question the patient asks is, "Doctor, what have I got?" Once the diagnosis is given, the next question is, "how bad is it?" or "how far has it gone?" The question that follows is, "what are you going to do about it?" The other question is always about the future: "how long will it take for me to get better?"

All seasoned physicians know how simple these questions are, but also profound, due to the impact of diagnosis on the patient: the fears, concerns, and perceptions. How many of us claim we have satisfactory and scientific answers to the simple questions by the patient with regard to COVID-19 diagnosis? Pfefferbaum and North ${ }^{45)}$ describe a range of emotional reactions-depressive and anxiety disorders-in COVID-19 patients. There is insecurity, confusion, emotional isolation, and stigma. ${ }^{45)}$ Many patients who evolve to a severe stage of COVID-19 already have high-risk factors such as kidney disease, diabetes, and cancer. These patients are also elderly, scared, and stressed about other family members being affected. Extance ${ }^{46)}$ provides guidance on dealing with these vulnerable patients. Most patients with severe CO-
VID-19 will be required to be taken care of in the most undesirable medical environmental conditions that compound their physical and mental suffering. The ride on the ambulance, caregivers and providers in PPE making them appear like aliens or astronauts at best, inability to hear instructions or interact with family members, needle sticks, lines, and wires, and finally some 'unconscious relief' on invasive mechanical ventilators. Even if they become conscious on ventilators, they cannot eat or talk, and are placed in an uncomfortable prone position for lung-saving ventilation. Rose et al. ${ }^{47)}$ vividly describes how visiting restrictions on family members cause moral injury to intensive care nursing staff. Ekberg et al. ${ }^{48)}$ provide a rapid review of communicating difficult matters in the context of COVID-19.

\section{GENERAL IMPACT OF COVID-19 DIAGNOSIS ON THE PATIENT'S LIFE}

The impact of COVID-19 on a patient's life depends on the currently known staging of the disease. Unlike staging of severe diseases like cancer, for which long standing experience, guidelines and evidencebased medicine exist, COVID-19 as a new disease has clinical staging lacking evidence base. However, the impact on a patient's life may become evident within days to weeks of diagnosis by molecular testing. If the patient has pre-existing risk factors such as chronic lung disease, diabetes, or cardiovascular conditions, or is elderly and frail, precipitous decline in mild stage may occur, within 1 week of mild symptom onset. Mild disease may transition to moderate disease with increasing dyspnea, lung infiltration, or hospitalization. This is followed by severe disease. $^{49)}$

\section{SPECIFIC IMPACTS OF DIAGNOSIS OF COVID-19: TANGIBLES AND INTANGIBLES}

\section{SARS-CoV-2 Is the Virus That Causes COVID-19}

It is important for clinicians to have good knowledge about the biology of this virus, particularly to answer the patient's questions and educate

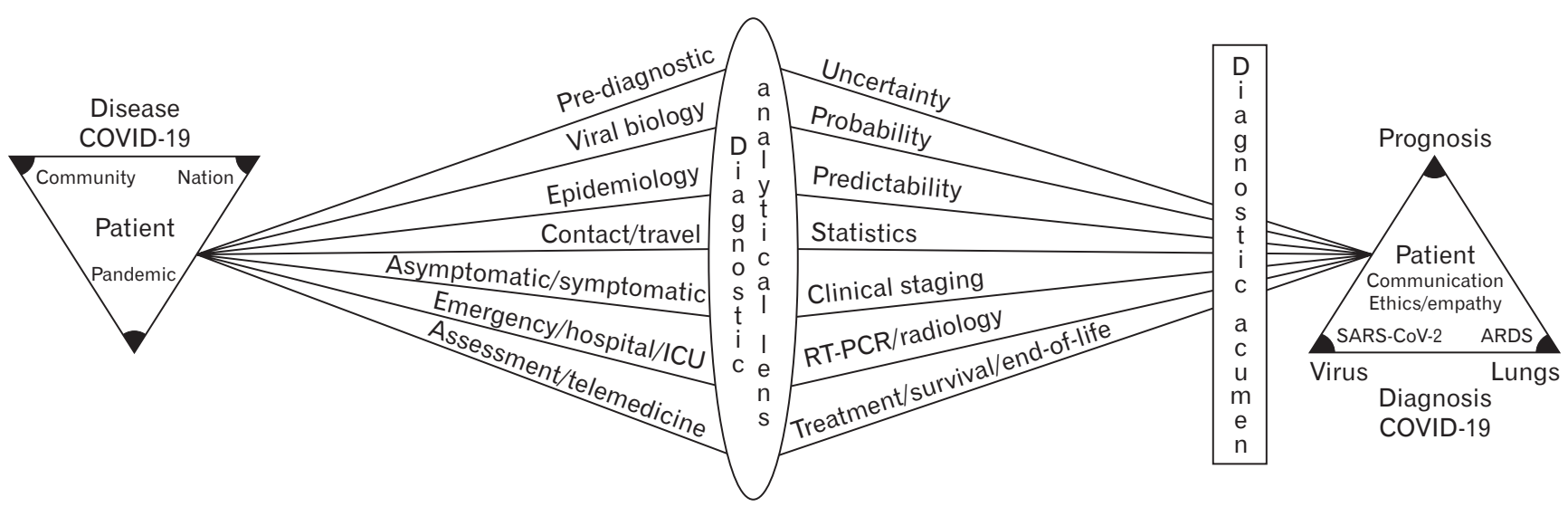

Figure 1. Complexity of coronavirus disease 2019 (COVID-19) diagnosis in the context of infectivity and pandemicity. RT-PCR, reverse transcriptase-polymerase chain reaction; ICU, intensive care unit; SARS-CoV-2, severe acute respiratory syndrome coronavirus 2; ARDS, acute respiratory distress syndrome. 


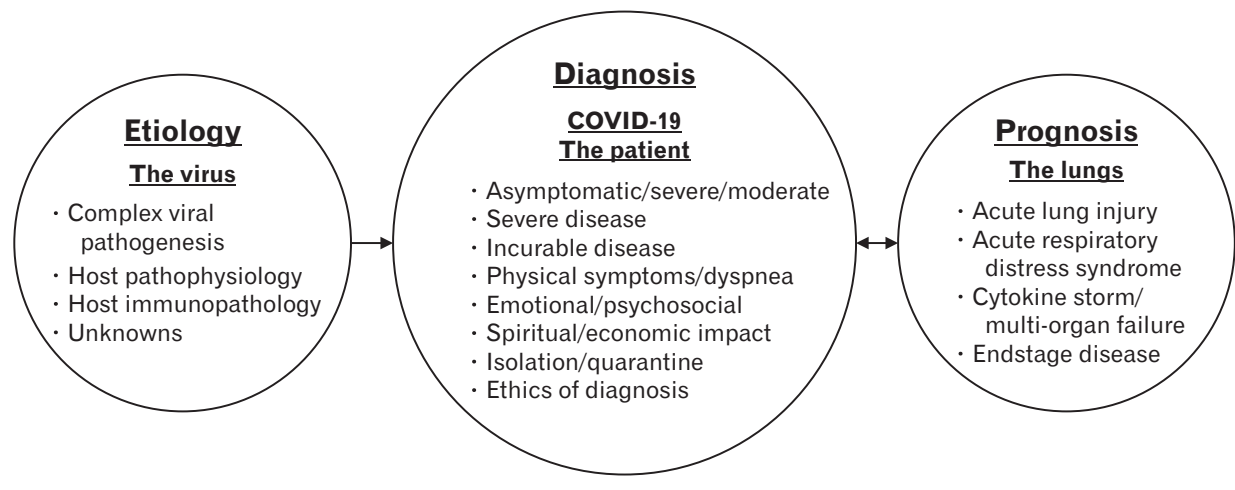

Figure 2. Human impact on the diagnosis of coronavirus disease 2019 (COVID-19): tangibles and intangibles. them on the transmission and control of infection by public health methods (Figure 2).

We observed how news media and social media bombard the population with information about the virus. On one hand, they call the virus invisible; on the other hand, they portray the virus as a multi-colored organism with spiny projections. Of course, lay people do not know whether the electron microscope or the image is a color rendition. The coronavirus is an RNA virus that can cause a common cold or a pandemic. All three pandemics of coronavirus have the same zoonotic primary reservoir, the bat. The secondary reservoir for SARS was the civet cat (not truly a cat but resembling a mongoose); for MERS, the dromedary camel; and for COVID-19, the wild pangolin (insect eater). Human-to-human transmission occurs by droplets of respiratory secretion, entry of the virus through the cell wall of respiratory tract cells, pneumocytes, the virus with its genetic nucleotide materials using host cellular apparatus to replicate its own RNA, capsid proteins, cell wall protein structures, and emergence out of cells as infectious virions to attack fresh cells. This whole process, including SARS-CoV and SARS-CoV-2 viruses, using the same human blood pressure receptor (angiotensin converting enzyme-2) on the cell wall to gain entry into the cells and initiate pathogenesis, is of great interest. A account of Weiss and Navas-Martin ${ }^{50)}$ of the viral biology of SARS-CoV is similar to science fiction.

An excellent review is available by Meo et al. ${ }^{51)}$ on all three coronaviruses responsible for the pandemics of this century. The complications related to the pathogenicity of COVID-19 is well described "cytokine storm" is another feature, with high fever, thrombocytopenia, hyperferritinemia and increased inflammatory marker C-reactive protein. ${ }^{52)}$ This immune response is also known as cytokine release syndrome and a hyperinflammatory response. ${ }^{53)}$

\section{The Lungs}

The hallmark of all three coronavirus pandemics is severe acute respiratory syndrome in the severe stages. In fact, the first pandemic disease was simply named "SARS." The second pandemic disease was named MERS, dropping the terms severe and acute. In the third pandemic, the disease was named COVID-19 dropping the terms severe, acute, and respiratory syndromes. In a review by Chu et al., ${ }^{54)} \mathrm{a}$ com- parison of SARS-CoV and SARS-CoV-2 showed similarities in their tropism, replication, kinetics, and pneumocyte cell damage, with implications for clinical manifestations, transmissibility, and laboratory studies.

Therefore, in our diagnostic acumen, we believe that pneumonia in COVID-19 is not a new diagnosis. All three pandemics, of SARS, MERS, and COVID-19, involved ARDS that fulfilled the Berlin definition of ARDS. ${ }^{55)}$ ARDS was defined as a type of acute, diffuse, inflammatory lung injury, leading to increased vascular permeability, increased lung weight, and loss of arterial lung tissue. Clinical hallmarks are hypoxemia and bilateral lung radiologic opacities, with morphological hallmarks of diffuse alveolar damage (DAD). Most patients were identified within 3-7 days of recognition of the underlying risk, with the onset within 7 days of known clinical insult. Gralinski and Baric ${ }^{56)}$ vividly described the molecular pathology of ARDS in coronavirus infections. Severity and outcome determined by immunopathological response, decreased surfactant, increased surface tension, decreased ability to expand and contract, risk of lung collapse, overwhelming cytokine response with DAD, and respiratory failure. ${ }^{56)}$ They also describe acute lung injury due to viral infection, leading to severe ARDS due to sepsis, mechanical trauma, chemical injury, influenza, and other viruses. The term ARDS was preferred because it adds 'distress' to acute respiratory failure, which is the cause of intense suffering in COVID-19.

\section{DIAGNOSIS OF CHRONIC COMPLEX NON- COMMUNICABLE DISEASES IN COVID-19 PATIENTS}

It is important to keep in mind that many COVID-19 patients are elderly and suffer from non-communicable diseases requiring timely assessment and management, irrespective of COVID-19 diagnosis. The following diseases are capable of causing morbidity and mortality during COVID-19 infection: cardiovascular diseases, stroke, end-stage renal disease, hypertension, diabetes mellitus, and chronic lung diseases. The current shift from onsite to remote assessment of these conditions by telemedicine may be difficult. As Domeyer et al. ${ }^{57)}$ puts it, "chronic non-communicable diseases should not become sacrificed on the altar of COVID-19." 


\section{ETHICS OF DIAGNOSING COVID-19}

Physicians have the "diagnostic duty" to inform of the diagnosis of COVID-19 and the implications of the diagnosis in a pandemic situation with highly infectious diseases such as COVID-19. Physicians may have an ethical or legal obligation to notify public health authorities of a patient's diagnosis or participation in data sharing with infectious disease registries. The American Medical Association ${ }^{58)}$ has provided excellent guidelines for physicians regarding the ethics of diagnosis of COVID-19.

\section{COVID-19 DIAGNOSIS AND DEATH CERTIFICATES}

Filling in a death certificate for any deceased patient requires accuracy in filling the diagnosis, and the death certificate is a document to be filled with respect to the deceased patient and the family. An accurate count of the number of deaths due to COVID-19, which depends in part on proper death certification, is critical to ongoing public health surveillance and response. Since COVID-19 is a new diagnosis, considerable confusion exists in the accurate diagnosis in death certificates. The following information obtained from the National Center for Health Statistics in the United States may be helpful for certifying death due to COVID-19. ${ }^{59}$

Physicians may wonder if "COVID-19" is an abbreviation and whether we need a full form. However, COVID-19 is an accurate and WHO-approved name for the disease in the United States and internationally and to be written as such.

- COVID-19 is not the underlying cause of death.

- Underlying causes of death are all conditions leading to death but not the cause of death.

- Pneumonia is not the cause of death but the intermediate cause of death.

- 'Viral infection' is not specific.

- COVID-19 is the disease condition that directly preceded death.

- "Manner of death" in COVID-19 is almost always filled as "natural."

- Do not put respiratory failure as a manner of death.

- Therefore, COVID-19 is the correct cause of death because it directly preceded death.

\section{COVID-19 DIAGNOSIS: WHOSE DIAGNOSTIC ACUMEN?}

Patient: Yes, the patient is called upon to undergo diagnosis of COVID-19 first because of quarantine or everyone is advised to call the doctor. There may not be a COVID-19 diagnosis if a patient does not recognize symptoms for diagnosis, and the diagnosis may be delayed.

Triage nurse: Nurses or similar professionals designated by physicians take the patient's phone call and advise the patient to stay home or make "forward triage" to go to a clinic or emergency room.

Primary care physician: May encounter COVID-19 patients initially at an early undifferentiated stage as most presenting symptoms are non-specific and cannot "clinch" the COVID-19 diagnosis.

\section{The "Flag System" for Diagnosis}

We recommend the need to recognize "red flags" for a serious condition that carries a likelihood of immediate or impending disability or death. Red flags should be identified early, usually during the historytaking process. For example, chest pain radiating to the neck or shoulder, diaphoresis, and palpitations may indicate possible acute myocardial infarction. Standard red flags exist in many fields of medicine. Ramanayake and Basnayake ${ }^{60)}$ provide very good guidance for the evaluation of red flags and minimize missing serious diseases in primary care.

For COVID-19, the red flags are moderate or severe symptoms, particularly those related to the respiratory system, as we have seen in several reviews and guidelines. Miller ${ }^{61)}$ describes flags of other colors in chiropractic.

We believe that these may apply to mild-to-moderate state of COVID-19, as follows: yellow for emotional/behavior issues (isolation, quarantine), black for occupational issues (unemployment due to quarantine), and blue for social and economic circumstances (family separation, dependent elderly patients, etc.). Orange flag for psychiatric elements (anxiety, depression, and demoralization during the pandemic). Diagnostic acumen in highly infectious diseases like COVID-19 in the context of a pandemic first requires a high index of suspicion, which we will assign to the white flag.

\section{Probable Diagnosis or Definite Diagnosis of COVID-19}

Lei et al. ${ }^{62)}$ provided the best interpretations for the molecular diagnostic test RT-PCR.

1) Initial RT-PCR test positive

- Possible infection, regardless of the presence or absence of other factors

2) Negative PCR: symptoms of cough, shortness of breath, chest computed tomography (CT) positive, history of exposure to another person with COVID-19

- Every probability of COVID-19 in an area of a high rate of infection

3) Initial RT-PCR test negative, and subsequent RT-PCR positive: history of exposure to COVID-19; follow-up chest CT shows progression

- Possible infection

4) Initial RT-PCR test negative: chest CT finding negative; laboratory results negative; not exposed to infected people

- Very probably no infection

5) RT-PCR test verified positive: chest laboratory results positive; symptomatic and suspected COVID-19

- Definite infection 


\section{3. "Front Line" Diagnosis of COVID-19}

The infectivity and human-to-human transmission of COVID-19 in a matter of a few days was so powerful that even the super-powers, Europe and the United States, were overwhelmed to the verge of collapse of emergency healthcare systems. Every physician/nurse of any specialty was called upon to manage the emergency, hospital, and intensive care unit systems, who had not worked in these sites before. For example, Sarpong et al. ${ }^{63)}$ describe compassionately how an entire orthopedic department was redeployed to the hospital and emergency services.

Medical students were called upon to manage COVID-19 patients. ${ }^{64)}$ Infectious disease specialists could diagnose and treat COVID-19. Walensky et al. ${ }^{65)}$ conducted an interesting study to examine how the distribution of infectious disease specialists matches the needs of the COVID-19 pandemic across the United States; they concluded that the availability of infectious disease physicians during pandemic times was too sparse, with 1-76 infectious disease specialists per 100,000 persons. Therefore, infectious disease diagnosis and management of COVID-19 became what we will call "front line diagnosis" in emergency management situations in the hospital. Obviously, the diagnosis in the emergency room and ICU has to be ultra-quick and focused on respiratory distress and acute organ failure, irrespective of confirmation of the diagnosis of COVID-19.

\section{PALLIATIVE CARE DIAGNOSIS: THE BLIND SPOT IN THE DIAGNOSIS OF SEVERE COVID-19}

The WHO's definition of palliative care is an approach that improves the quality of life of patients and their families facing problems associated with life-threatening illness through prevention and impeccable assessment and treatment of pain and other problems, such as physical, psychosocial, and spiritual problems. ${ }^{66)}$ The WHO also has guidelines on COVID-19 for the treatment of severe acute respiratory infections. However, there is no direct mention of palliative care, except that palliative care goals are indirectly stated in the care of elderly persons with COVID-19. ${ }^{67}$

Here, we discuss palliative care in the context of a severe stage of COVID-19 and not asymptomatic or mild-to-moderate stages. COVID-19 in the severe stage of the infection is an advanced, incurable disease with rare exceptions. It manifests as physical symptoms, including acute respiratory distress, emotional symptoms of anxiety, depression, and delirium in the environment of isolation, emergency, and ICU setting. Patients suffer from psychosocial issues, family separation, and spiritual anger with fear of dying. A large percentage of patients reach end-of-life with a life expectancy of hours to days. These patients are eminently suitable for palliative end-of-life care. Patients suffering from ARDS or cytokine storm and organ failure should be diagnosed for the suitability of palliative care. Therefore, COVID-19 in the severe stage carries a dual diagnosis of severe infection and palliative end-oflife care.

Our idea of palliative care for the diagnosis of the coronavirus pan- demic is not new. When the SARS pandemic occurred in 2002, Chen et al. ${ }^{68)}$ reported that 818 patients were admitted to inpatient wards for palliative care. Downar et al. ${ }^{69)}$ predicted a COVID-19-like pandemic and outlined a comprehensive palliative care plan for palliating a pandemic by stating that "all patients must be cared for." We emphasize that palliative care in COVID-19 is essential to determine the diagnosis of terminal illness with great distress, lest the patient and family miss out on comforting palliative care.

It is not true that every patient with COVID-19 in the emergency room or ICU suffering from ARDS is dying. Patients may be stable, unstable, or at the end of their life. It may still be argued that palliative care can be provided with a rapidly escalating model of care in the emergency room or ICU, while a non-escalating model of care is preferred in palliative care. Fusi-Schmidhauser et al. ${ }^{70)}$ proposed and developed innovative 'emergency palliative care action' for conservative management of COVID-19 patients; they have also developed a specific diagnostic assessment tool with three 'D's: dyspnea, distress, and discomfort. The emergency style of palliative care can provide comfort for patients who are deteriorating rapidly. ${ }^{70)}$

\section{COMMUNICATION OF DIAGNOSIS TO THE PATIENT AND FAMILY: ACUMEN REQUIRED IN CLOSING THE LOOP OF DIAGNOSIS OF COVID-19}

The most important element in the diagnostic acumen for COVID-19 is communication skills that provide information on diagnosis to patients and their families. This is bound to evoke a fear of death and suffering. Therefore, breaking this sad and bad news requires sensitivity, sympathy, empathy, and compassion, whether face-to-face with a mask on, or through several layers of PPE or remotely by telemedicine.

\section{CONCLUSION}

Science and technology may be able to view the virus on a cell; fuse with the cell wall; enter the cell; and use the host cell apparatus to replicate itself with genes, enzymes, and proteins; but in this third coronavirus epidemic, we still need the diagnostic acumen for accurate and timely diagnosis. We still need to acquire knowledge regarding the pathogenicity, pathophysiology, immunology, and host responses to facilitate the discovery of a cure or prophylaxis. Diagnostic acumen is the most important link between etiology and treatment.

Martin and Martin-Granel ${ }^{71)}$ provide an interesting account of the evolution of the term epidemiology. Hippocrates discussed epidemics 2,300 years ago. ${ }^{71)}$ The adjective of the term is "epidemios" meaning "which circulates or propagates in a country." It is so uncanny or ominous scientifically or a coincidence that Kelly-Cirino et al. ${ }^{72)}$ submitted their paper to BMJ Global Health before the COVID-19 pandemic in September 2018, published early in 2019, on diagnostics and preparedness in epidemic or pandemic situations. Their analysis showed that six out of ten WHO blueprint priority diseases of pandemics have significant diagnostic gaps. Wu and Lowenstein ${ }^{73)}$ emphasized that di- 
agnoses are hypotheses that help to maintain humility and not overconfidence. Humility acknowledges ambiguities, uncertainties, strengths, and emotional resilience. ${ }^{73)}$

Above all, it is our duty to diagnose COVID-19 accurately and promptly and communicate with patients and families with empathy and ethics. Excellence in diagnostic acumen defines our service to patients.

\section{CONFLICT OF INTEREST}

No potential conflict of interest relevant to this article was reported.

\section{ORCID}

Suresh K. Joishy: https://orcid.org/0000-0001-8793-8250

Michito Sadohara: https://orcid.org/0000-0003-3095-676X

Masaru Kurihara: https://orcid.org/0000-0001-9195-4202

Yasuharu Tokuda: https://orcid.org/0000-0002-9325-7934

\section{REFERENCES}

1. Chinese Center for Disease Control and Prevention. COVID19 [Internet]. Beijing: Chinese Center for Disease Control and Prevention; 2020 [cited 2020 Jul 23]. Available from: http://www.chinacdc.cn/en/COVID19/.

2. Wu Z, McGoogan JM. Characteristics of and important lessons from the coronavirus disease 2019 (COVID-19) outbreak in China: summary of a report of 72314 cases from the Chinese Center for Disease Control and Prevention. JAMA 2020;323:1239-42.

3. Anderson RM, Heesterbeek H, Klinkenberg D, Hollingsworth TD. How will country-based mitigation measures influence the course of the COVID-19 epidemic? Lancet 2020;395:931-4.

4. Vihinen M. Strategy for disease diagnosis, progression prediction, risk group stratification and treatment: case of COVID-19. Front Med (Lausanne) 2020;7:294.

5. Peiris JS, Yuen KY, Osterhaus AD, Stohr K. The severe acute respiratory syndrome. N Engl J Med 2003;349:2431-41.

6. Assiri A, Al-Tawfiq JA, Al-Rabeeah AA, Al-Rabiah FA, Al-Hajjar S, AlBarrak A, et al. Epidemiological, demographic, and clinical characteristics of 47 cases of Middle East respiratory syndrome coronavirus disease from Saudi Arabia: a descriptive study. Lancet Infect Dis 2013;13: $752-61$.

7. Borges do Nascimento IJ, Cacic N, Abdulazeem HM, von Groote TC, Jayarajah U, Weerasekara I, et al. Novel coronavirus infection (COVID-19) in humans: a scoping review and meta-analysis. J Clin Med 2020;9:941.

8. Richardson S, Hirsch JS, Narasimhan M, Crawford JM, McGinn T, Davidson $\mathrm{KW}$, et al. Presenting characteristics, comorbidities, and outcomes among 5700 patients hospitalized with COVID-19 in the New York city area. JAMA 2020;323:2052-9.

9. Song JY, Yun JG, Noh JY, Cheong HJ, Kim WJ. COVID-19 in South Korea: challenges of subclinical manifestations. N Engl J Med 2020;382: 1858-9.
10. Lum LH, Tambyah PA. Outbreak of COVID-19: an urgent need for good science to silence our fears? Singapore Med J 2020;61:55-7.

11. Furuse Y, Ko YK, Saito M, Shobugawa Y, Jindai K, Saito T, et al. Epidemiology of COVID-19 outbreak in Japan, from January-March 2020. Jpn J Infect Dis 2020;73:391-3.

12. Saglietto A, D'Ascenzo F, Zoccai GB, De Ferrari GM. COVID-19 in Europe: the Italian lesson. Lancet 2020;395:1110-1.

13. World Health Organization. Report of the WHO-China joint mission on coronavirus disease 2019 (COVID-19) [Internet]. Geneva: World Health Organization; 2020 [cited 2020 Jul 21]. Available from: https:// www.who.int/docs/default-source/coronaviruse/who-china-jointmission-on-covid-19-final-report.pdf.

14. BMJ Publishing Group. Coronavirus disease 2019 (COVID-19) [Internet]. London: BMJ Publishing Group; 2020 [cited 2020 Jul 21]. Available from: https://bestpractice.bmj.com/topics/en-us/3000168/investigations.

15. Centers for Disease Control and Prevention. CDC: COVID-19 testing: what you need to know [Internet]. Atlanta (GA): Centers for Disease Control and Prevention; [date unknown] [cited 2020 Jul 21]. Available from: https://www.cdc.gov/coronavirus/2019-ncov/symptoms-testing/testing.html.

16. Bhimraj A, Morgan RL, Shumaker AH, Lavergne V, Baden L, Cheng VC, et al. Infectious Diseases Society of America guidelines on the treatment and management of patients with COVID-19. Clin Infect Dis 2020 Apr 27 [Epub]. https://doi.org/10.1093/cid/ciaa478.

17. Centers for Disease Control and Prevention. CDC: COVID-19 guidelines [Internet]. Atlanta (GA): Centers for Disease Control and Prevention; 2020 [cited 2020 Jul 21]. Available from: https://www.cdc.gov/ coronavirus/2019-ncov/index.html.

18. World Health Organization. Country \& technical guidance: coronavirus disease (COVID-19) [Internet]. Geneva: World Health Organization; 2020 [cited 2020 Jul 21]. Available from: https://www.who.int/ emergencies/diseases/novel-coronavirus-2019/technical-guidance.

19. National Institute for Health and Care Excellence. NICE Guidelines: COVID-19 [Internet]. London: National Institute for Health and Care Excellence; 2020 [cited 2020 Jul 21]. Available from: https://www.nice. org.uk/guidance/conditions-and-diseases/respiratory-conditions/ covid19.

20. Chavez S, Long B, Koyfman A, Liang SY. Coronavirus disease (COVID-19): a primer for emergency physicians. Am J Emerg Med 2021;44: 220-9.

21. Jiang F, Deng L, Zhang L, Cai Y, Cheung CW, Xia Z. Review of the clinical characteristics of coronavirus disease 2019 (COVID-19). J Gen Intern Med 2020;35:1545-9.

22. Card AJ. Pandemicity and severity are separate constructs. Am J Public Health 2012;102:e12.

23. Fauci AS, Lane HC, Redfield RR. COVID-19: navigating the uncharted. N Engl J Med 2020;382:1268-9.

24. Centers for Disease Control and Prevention. United States COVID-19 cases and deaths by state [Internet]. Atlanta (GA): Centers for Disease Control and Prevention; 2020 [cited 2020 Jul 21]. Available from: https://www.cdc.gov/covid-data-cracker.

25. Lippi G, Sanchis-Gomar F, Henry BM. Coronavirus disease 2019 (COVID-19): the portrait of a perfect storm. Ann Transl Med 2020;8:497. 26. Wynants L, Van Calster B, Collins GS, Riley RD, Heinze G, Schuit E, et 
al. Prediction models for diagnosis and prognosis of COVID-19: systematic review and critical appraisal. BMJ 2020;369:m1328.

27. Collins Dictionary. Acumen [Internet]. Glasgow: Collins Dictionary; 2020 [cited 2020 Jul 21]. Available from: https://www.collinsdictionary.com/dictionary/english/acumen.

28. Merriam Webster Dictionary. Acumen [Internet]. Springfield (MA): Merriam Webster Dictionary; 2020 [cited 2020 Jul 21]. Available from: https://www.merriam-webster.com/dictionary/acumen.

29. Tang YW, Schmitz JE, Persing DH, Stratton CW. Laboratory diagnosis of COVID-19: current issues and challenges. J Clin Microbiol 2020;58: e00512-20.

30. Watson J, Whiting PF, Brush JE. Interpreting a COVID-19 test result. BMJ 2020;369:m1808.

31. Patel R, Babady E, Theel ES, Storch GA, Pinsky BA, St George K, et al. Report from the American Society for Microbiology COVID-19 International Summit, 23 March 2020: value of diagnostic testing for SARSCoV-2/COVID-19. mBio 2020;11:e00722-20.

32. Whitcroft KL, Hummel T. Olfactory dysfunction in COVID-19: diagnosis and management. JAMA 2020;323:2512-4.

33. Galvan Casas C, Catala A, Carretero Hernandez G, Rodriguez-Jimenez P, Fernandez-Nieto D, Rodriguez-Villa Lario A, et al. Classification of the cutaneous manifestations of COVID-19: a rapid prospective nationwide consensus study in Spain with 375 cases. Br J Dermatol 2020;183:71-7.

34. World Health Organization. Coronavirus disease (COVID-19) pandemic [Internet]. Geneva: World Health Organization; 2020 [cited 2020 Jul 21]. Available from: https://www.who.int/emergencies/diseases/ novel-coronavirus-2019?gclid=Cj0KCQjw3ZX4BRDmARIsAFYh7ZKZ XxZnwPy4HcZYVOi9clihwjBCchdYL1NShjnYhuZNhL3CFnzehXEa AiwmEALw_wcB.

35. Helmy YA, Fawzy M, Elaswad A, Sobieh A, Kenney SP, Shehata AA. The COVID-19 pandemic: a comprehensive review of taxonomy, genetics, epidemiology, diagnosis, treatment, and control. J Clin Med 2020;9:1225.

36. Greenberg N, Docherty M, Gnanapragasam S, Wessely S. Managing mental health challenges faced by healthcare workers during COVID-19 pandemic. BMJ 2020;368:m1211.

37. Wilder-Smith A, Chiew CJ, Lee VJ. Can we contain the COVID-19 outbreak with the same measures as for SARS? Lancet Infect Dis 2020;20: e102-7.

38. Wong GW, Hui DS. Severe acute respiratory syndrome (SARS): epidemiology, diagnosis and management. Thorax 2003;58:558-60.

39. Contini C, Di Nuzzo M, Barp N, Bonazza A, De Giorgio R, Tognon M, et al. The novel zoonotic COVID-19 pandemic: an expected global health concern. J Infect Dev Ctries 2020;14:254-64.

40. Centers for Disease Control and Prevention. SARS [Internet]. Atlanta (GA): Centers for Disease Control and Prevention; 2009 [cited 2020 Jul 23]. Available from: https://stacks.cdc.gov/view/cdc/24776.

41. Centers for Disease Control and Prevention. Middle east respiratory syndrome (MERS) [Internet]. Atlanta (GA): Centers for Disease Control and Prevention; 2019 [cited 2020 Jul 23]. Available from: https:// www.cdc.gov/coronavirus/mers/index.html.

42. Widders A, Broom A, Broom J. SARS-CoV-2: the viral shedding vs infectivity dilemma. Infect Dis Health 2020;25:210-5.

43. Gandhi TK, Singh H. Reducing the risk of diagnostic error in the COV-
ID-19 era. J Hosp Med 2020;15:363-6.

44. Rong XM, Yang L, Chu HD, Fan M. Effect of delay in diagnosis on transmission of COVID-19. Math Biosci Eng 2020;17:2725-40.

45. Pfefferbaum B, North CS. Mental health and the COVID-19 pandemic. N Engl J Med 2020;383:510-2.

46. Extance A. COVID-19 and long term conditions: what if you have cancer, diabetes, or chronic kidney disease? BMJ 2020;368:m1174.

47. Life Lines Team comprising, Rose L, Cook A, Casey J, Meyer J. Restricted family visiting in intensive care during COVID-19. Intensive Crit Care Nurs 2020;60:102896.

48. Ekberg S, Parry R, Land V, Ekberg K, Pino M, Antaki C. Communicating with patients and families about difficult matters: a rapid review in the context of the COVID-19 pandemic. medRxiv [Preprint] 2020 Jan 1 [Epub]. https://doi.org/10.1101/2020.04.27.20078048.

49. Gandhi RT, Lynch JB, Del Rio C. Mild or Moderate COVID-19. N Engl J Med 2020;383:1757-66.

50. Weiss SR, Navas-Martin S. Coronavirus pathogenesis and the emerging pathogen severe acute respiratory syndrome coronavirus. Microbiol Mol Biol Rev 2005;69:635-64.

51. Meo SA, Alhowikan AM, Al-Khlaiwi T, Meo IM, Halepoto DM, Iqbal M, et al. Novel coronavirus 2019-nCoV: prevalence, biological and clinical characteristics comparison with SARS-CoV and MERS-CoV. Eur Rev Med Pharmacol Sci 2020;24:2012-9.

52. Berlin DA, Gulick RM, Martinez FJ. Severe COVID-19. N Engl J Med 2020;383:2451-60.

53. Yazdanpanah F, Hamblin MR, Rezaei N. The immune system and COVID-19: friend or foe? Life Sci 2020;256:117900.

54. Chu H, Chan JF, Yuen TT, Shuai H, Yuan S, Wang Y, et al. Comparative tropism, replication kinetics, and cell damage profiling of SARS-CoV-2 and SARS-CoV with implications for clinical manifestations, transmissibility, and laboratory studies of COVID-19: an observational study. Lancet Microbe 2020;1:e14-23.

55. ARDS Definition Task Force, Ranieri VM, Rubenfeld GD, Thompson BT, Ferguson ND, Caldwell E, et al. Acute respiratory distress syndrome: the Berlin Definition. JAMA 2012;307:2526-33.

56. Gralinski LE, Baric RS. Molecular pathology of emerging coronavirus infections. J Pathol 2015;235:185-95.

57. Domeyer P, Katsari V, Mariolis A. Chronic non-communicable diseases: a sacrifice on the altar of COVID-19? Br J Gen Pract 2020;70:281.

58. American Medical Association. AMA code of medical ethics: guidance in a pandemic [Internet]. Chicago (IL): American Medical Association; 2020 [cited 2020 Jul 23]. Available from: https://www.ama-assn.org/ delivering-care/ethics/ama-code-medical-ethics-guidance-pandemic.

59. Anderson RN, Warner M, Anne L, Ahmad F. Guidance for certifying deaths due to coronavirus disease 2019 (COVID-19). Atlanta (GA): Centers for Disease Control and Prevention; 2020.

60. Ramanayake RP, Basnayake BM. Evaluation of red flags minimizes missing serious diseases in primary care. J Family Med Prim Care 2018;7:315-8.

61. Miller KJ. Know your clinical flags: 5 different colors to consider [Internet]. Huntington Beach (CA): Dynamic Chiropractic; 2020 [cited 2020 Jul 21]. Available from: https://www.dynamicchiropractic.com/mpacms/dc/article.php?id=58344.

62. Lei P, Fan B, Wang P. Differential diagnosis for coronavirus disease (COVID-19): beyond radiologic features. AJR Am J Roentgenol 2020; 
215:W19.

63. Sarpong NO, Forrester LA, Levine WN. What's important: redeployment of the orthopaedic surgeon during the COVID-19 pandemic: perspectives from the trenches. J Bone Joint Surg Am 2020;102:101921.

64. Miller DG, Pierson L, Doernberg S. The role of medical students during the COVID-19 pandemic. Ann Intern Med 2020;173:145-6.

65. Walensky RP, McQuillen DP, Shahbazi S, Goodson JD. Where is the ID in COVID-19? Ann Intern Med 2020;173:587-9.

66. World Health Organization. WHO definition of palliative care [Internet]. Geneva: World Health Organization; 2020 [cited 2020 Jul 21]. Available from: https://www.who.int/news-room/fact-sheets/detail/ palliative-care.

67. World Health Organization. Clinical management of severe acute respiratory infection (SARI) when COVID-19 disease is suspected [Internet]. Geneva: World Health Organization; 2020 [cited 2020 Jul 21].
Available from: https://apps.who.int/iris/handle/10665/331446.

68. Chen TJ, Lin MH, Chou LF, Hwang SJ. Hospice utilization during the SARS outbreak in Taiwan. BMC Health Serv Res 2006;6:94.

69. Downar J, Seccareccia D; Associated Medical Services Inc.; Educational Fellows in Care at the End of Life. Palliating a pandemic: "all patients must be cared for". J Pain Symptom Manage 2010;39:291-5.

70. Fusi-Schmidhauser T, Preston NJ, Keller N, Gamondi C. Conservative management of COVID-19 patients-emergency palliative care in action. J Pain Symptom Manage 2020;60:e27-30.

71. Martin PM, Martin-Granel E. 2,500-year evolution of the term epidemic. Emerg Infect Dis 2006;12:976-80.

72. Kelly-Cirino CD, Nkengasong J, Kettler H, Tongio I, Gay-Andrieu F, Escadafal C, et al. Importance of diagnostics in epidemic and pandemic preparedness. BMJ Glob Health 2019;4(Suppl 2):e001179.

73. Wu J, Lowenstein E. Balancing confidence and humility in the diagnostic process. Diagnosis (Berl) 2020;7:11-5. 